\title{
Treatment and Recycling of Wastewater by Submerged Hollow Fiber Membrane
}

\author{
Dewen He, Huangnian Zhou, Lei Liu, Dingmin Liang, Lu Du
}

School of Metallurgical Science \& Engineerin, Central South University, Changsha, China.

E-mail: hedewen@mail.csu.edu.cn

Received October 10 ${ }^{\text {th }}, 2010$; revised April 11 ${ }^{\text {th }}, 2011$; accepted April 20 ${ }^{\text {th }}, 2011$.

\begin{abstract}
In this study, the effects of experimental conditions including the MBR equipped novel device and different operating modes on permeate flux were studied. The results show that the MBR equipped novel device can reduce the resistance and enhance the flux, decreasing the total resistance $\left(R_{t}=9.649\right)$ to 5.962 and increasing the permeate flux to 15-20 $l / m^{2} h r$. The permeate flux of intermittent operating mode is more than that of continuous operation and the value of the permeate flux is between $15 \mathrm{l} / \mathrm{m}^{2} \mathrm{hr}$ and $20 \mathrm{l} / \mathrm{m}^{2} \mathrm{hr}$. The MBR equipped novel device which adopting intermittent operating mode is most effective in this study and the value of permeate flux is between $20 \mathrm{l} / \mathrm{m}^{2} \mathrm{hr}$ and $25 \mathrm{l} / \mathrm{m}^{2} \mathrm{hr}$.
\end{abstract}

Keywords: Membrane Bioreactor, Separation, Fouling, Hollow Fiber Membrane

\section{Introduction}

Membrane bioreactor (MBR) is an effective technology for wastewater treatment and recycling, in which gravity settling of the activated sludge system is replaced by a membrane separation process such as micro-filtration (MF) or ultra-filtration (UF) [1-2]. The resulting highquality and disinfected effluent implies that MBR processes can be especially suitable for reuse and recycling of wastewater [3]. A major factor against the application of membrane micro-filtration or ultra-filtration with the activated sludge process is the flux decline due to membrane fouling [4-5].

Membrane fouling is often referred to as any form of flux decline [6]. This includes reversible effects (such as cake formation), as well as irreversible effects (such as adsorption). Concentration polarization, though it does cause a decline in membrane flux, is a phenomenon which occurs in solution, and will therefore not be considered a form of fouling. However, when speaking of reversible flux decline, or reversible hydraulic resistance, concentration polarization will be categorized with cake formation, since all of their effects can be reversed by the hydraulic back-flushing of the membrane. Irreversible flux decline, which is always a form of fouling, is caused primarily by the adsorption of natural organic matter (NOM) onto the surface or inside the pores of the membrane [7-8]. Though this fouling can be reversed by chemical treatment, it is not considered "reversible" since it cannot be reduced by standard physical processes.

During a long term operation, membranes are periodically back-washed by pumping a fraction of permeate back through the membranes [9-12]. Backwashing is used for removing the cake layer (reversible fouling). Concentration polarization is reduced by non-suction as well as reverse flow. Thus backwashing can remove reversible hydraulic resistance due to cake formation and concentration polarization. Backwashing entails reversal of the permeate flow and power consumption of backwashing pump.

In this paper, a novel device was introduced during the filtration. This device could be used to counteract fouling during filtration (especially for cake formation) without reverse flow. The behavior of MBR under the combination of this device and intermittent permeation was then observed.

\section{Materials and Methods}

\subsection{Activated Sludge MBR Operation}

The configuration of the activated sludge MBR system used in this study is schematically described in Figure 1. This system consisted of hollow fiber (HF) flat-plat membrane module and bioreactor, similar to typical MBR [13]. The bioreactor has a working volume of 301 . 


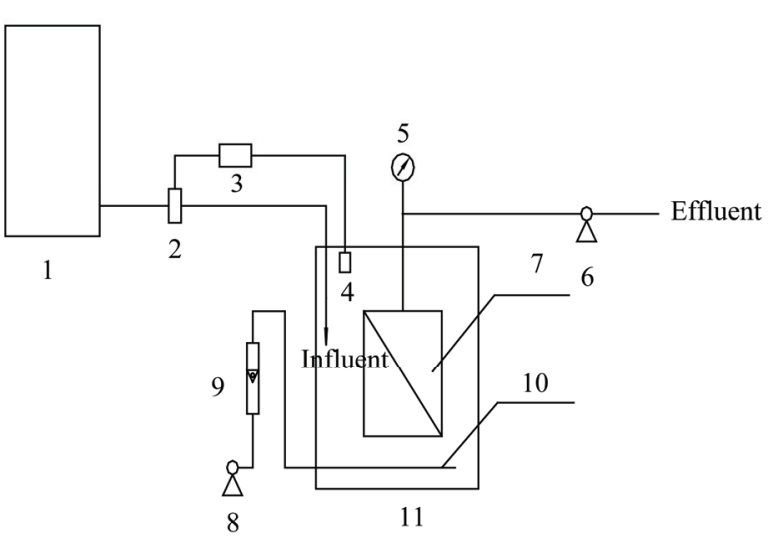

(1. feed tank, 2. electromagnetic valve, 3. level controller, 4. level probe 5. vacuum gauge, 6. pump, 7. fiber membrane, 8. pump, 9. flow meter, 10. aerator, 11. bioreactor solenoid e valve)

Figure 1. Configurations of activated sludge MBR system.

Table 1. Characteristics of the wastewater.

\begin{tabular}{cc}
\hline $\mathrm{COD}\left(\mathrm{mg} \cdot \mathrm{L}^{-1}\right)$ & $20 \sim 80$ \\
$\mathrm{NH}_{3}-\mathrm{N}\left(\mathrm{mg} \cdot \mathrm{L}^{-1}\right)$ & $4 \sim 18$ \\
$\mathrm{TP}\left(\mathrm{mg} \cdot \mathrm{L}^{-1}\right)$ & $0.3 \sim 2.0$ \\
\hline
\end{tabular}

The hydraulic retention time of the bioreactor was set to $6 \mathrm{~h}$ for the majority of experiments.

The wastewater used in the study was pumped from a local drain ditch. Characteristics of the wastewater are shown in Table 1.

\subsection{Membranes and Module Configuration}

The micro-filtration membranes were polypropylene hollow fibers with a pore size of 0.1-0.2 $\mu \mathrm{m}$. An effective filtration area was $0.25 \mathrm{~m}^{2}$.

In order to investigate the reversible resistance removal, the membranes has been continuously operated for two months prior to this study. Irreversible resistance (adsorption fouling) during this study reached steady and kept constant. To ensure that the condition and performance of the membrane module was almost the same in all experiments, backwashing was performed after every experiment to removing the reversible resistance.

\subsection{Membrane Performance Assessment}

The rate and extent of membrane fouling were quantified by measuring permeate flux at constant suction pressure, which is defined as permeate vol/unit membrane surface area and filtration time. The variation of membrane productivity was evaluated by plotting permeate flux against filtration time.

To characterize membrane fouling, the water flux was initially measured with tap water. Also, water flux was measured at each step of the cleaning procedure, that is, after taking out and putting the membrane module in tap water and then after flushing and backwashing the membrane module. The fluxes and filtration resistances were measured and calculated collectively.

\section{Results and Discussion}

\subsection{Continuous Operation}

The permeate flux decline with time during the membrane filtration of activated sludge was first studied with a polluted membrane. The permeate flux decreased sharply after the start of filtration, and reached a pseudosteady state after 2-3 h of operation.

The initial sharp decline in permeate flux observed was mainly due to concentration polarization and cake layer formation on the membrane surface. Further decrease in permeate flux over time was caused by the increased thickness of the cake layer due to additional foulant transport to the membrane surface, cake compaction and concentration polarization.

\subsection{Continuous Operation with the Novel Device}

In order to maintain a steady permeate flux during operation, the cake layer deposited on the membrane surface needs to be removed by a shear, which can be created by various means.

A novel device was employed to control concentration polarization and cake layer formation on the membrane surface. The fibers through this device made to-and-fro motion along the direction vertical to two pipes, and the continuous deformation of the fibers themselves created a shear to the cake layer on the membrane surface, and the mutual rubbing between the fibers due to the continuous deformation of the fibers also created a shear to the cake layer on the hollow fiber membrane. In addition, the continuous movement of the fibers in water enhanced the stirring of water on the membrane surface, and decreased concentration polarization.

Compared to continuous operation in Figure 2, continuous operation with the device reduced the rate and extent of membrane fouling [14-15].

The resistance-in-series model was applied to evaluate the characteristics of membrane fouling. According to this model, the permeation flux $(J)$ takes the following form.

$$
\begin{gathered}
J=\frac{\Delta p}{\eta R_{\mathrm{t}}} \\
R_{\mathrm{t}}=R_{\mathrm{m}}+R_{\mathrm{p}}+R_{\mathrm{rf}}+R_{\text {irf }}
\end{gathered}
$$

where $\Delta p$ is the transmembrane pressure; $\eta$ is the dynamic viscosity of the permeate; $R_{t}$ is the total resistance; $R_{m}$ is the intrinsic membrane resistance; $R_{p}$ 
is the polarization layer resistance caused by the concentration gradient; $R_{r f}$ is the reversible fouling resistance formed by a strongly deposited cake layer; $R_{\text {irf }}$ is the irreversible fouling resistance due to some irreversible adsorption. Here, the $R_{p}$ term experimentally defined as the portion of the total resistance dislodged only by water dropping of the membrane module and then immerging in tap water.

These equations and the flux data at the end of continuous operation with the novel device have been used to calculate the values of each resistance term given in Table 2.

Figure 2 shows that $R_{r f}$ (the percent of total resistance) was very small during continuous operation with the novel device and cake layer were almost removed due to this device.

\subsection{Non-Continuous Operation}

In general, the membrane coupled with bioreactors is continuously operated for the effective utilization of given membranes. Continuous membrane filtration, however, tends to increase fouling, thus decreasing permeate flux through the membrane over time. In this study, non-continuous suction operation was introduced as a fouling alleviating alternative. Figure 3 compares the continuous and non-continuous suction operation modes. Change in permeate flux was plotted in terms of time (28

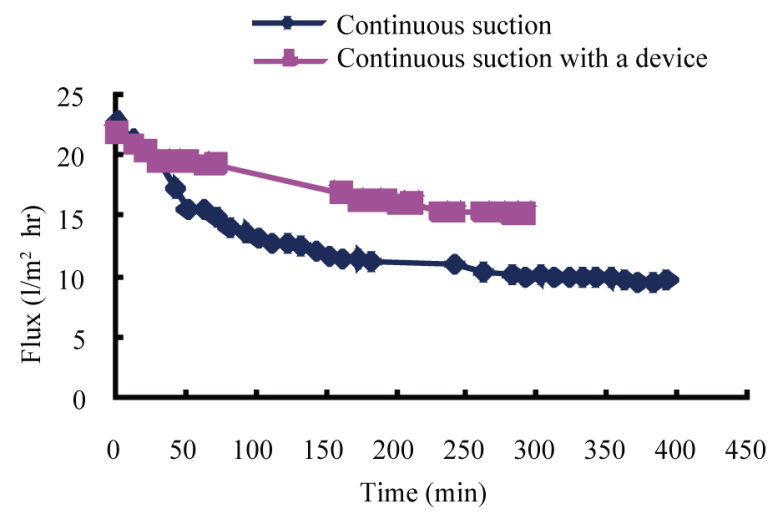

Figure 2. Flux variation with respect to time / 26kPa suction pressure.

Table 2. A series of resistances for the membrane at the end of continuous operation and continuous operation with the novel device.

\begin{tabular}{ccccc}
\hline & \multicolumn{2}{c}{ with this device } & \multicolumn{2}{c}{ without this device } \\
\hline Resistance & Value & Percentage* & Value & Percentage \\
& $\left(1012 \mathrm{~m}^{-1}\right)$ & $(\%)$ & $\left(1012 \mathrm{~m}^{-1}\right)$ & $(\%)$ \\
$R_{\mathrm{m}}+R_{\text {irf }}$ & 4.123 & 69.2 & 4.123 & 42.7 \\
$R_{\mathrm{p}}$ & 1.707 & 28.6 & 3.687 & 38.2 \\
$R_{\mathrm{rf}}$ & 0.132 & 2.2 & 1.839 & 19.1 \\
$R_{\mathrm{t}}$ & 5.962 & 100.0 & 9.649 & 100.0 \\
\hline
\end{tabular}

minutes' suction of 2 minutes' suspension). The results clearly showed that membrane performance was improved with intermittent suction. This finding can be explained by the enhanced foulant back transport under pressure relaxation. From Figure 3, as soon as transmembrane (suction) pressure was reduced to zero at non-suction period, the foulants not irreversibly attached to the membrane surface, diffused away from the membrane surface because of the concentration gradient. As a result, foulant accumulation near the membrane surface was lessened and the rate of membrane fouling was reduced.

Flux recovery by pressure relaxation has been reported by Hong et al. [10], who studied the ultra-filtration of activated sludge. Like their study, the permeate flux was only partially recovered, indicating that reversible hydraulic resistance due to cake formation and concentration polarization existed.

\subsection{Non-Continuous Operation with the Device}

With operation of the device, the cake layer was almost removed. After two minutes' pressure relaxation, concentration polarization was removed. As shown in Figure 4, almost $100 \%$ flux recovery was observed under the intermittent suction with the device. In consideration of long-term operation of fibers, the fibers kept loose and cannot tension during to-and-fro motion. Thus a portion of fibers close to catchments pipes hardly made continuous deformation and no movement of fibers. The cake layer on the membrane surface of this portion of fibers was not eliminated.

\section{Conclusions}

The MBR equipped novel device can improve the permeate flux. The value of the MBR equipped novel device is between $15 \mathrm{l} / \mathrm{m}^{2} \mathrm{hr}$ and $20 \mathrm{l} / \mathrm{m}^{2} \mathrm{hr}$. It is more than the

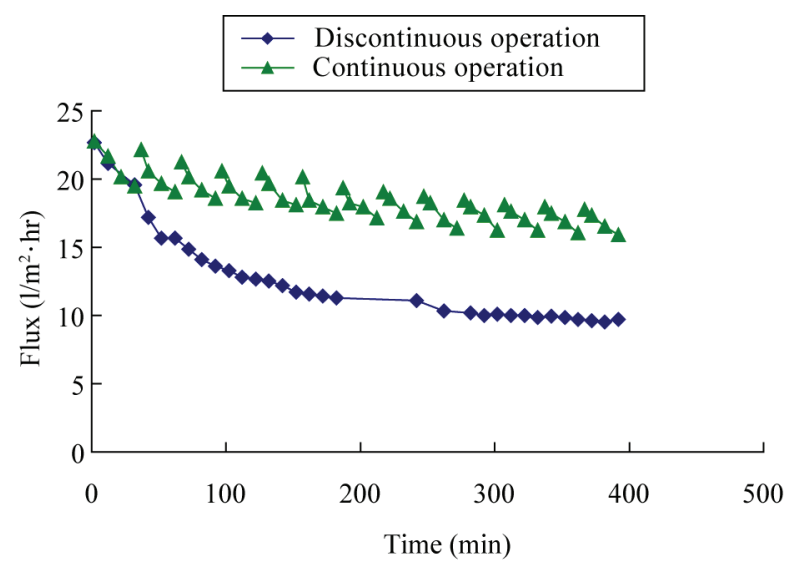

Figure 3. Flux variation with respect to time with a device / $26 \mathrm{kPa}$ suction pressure. 


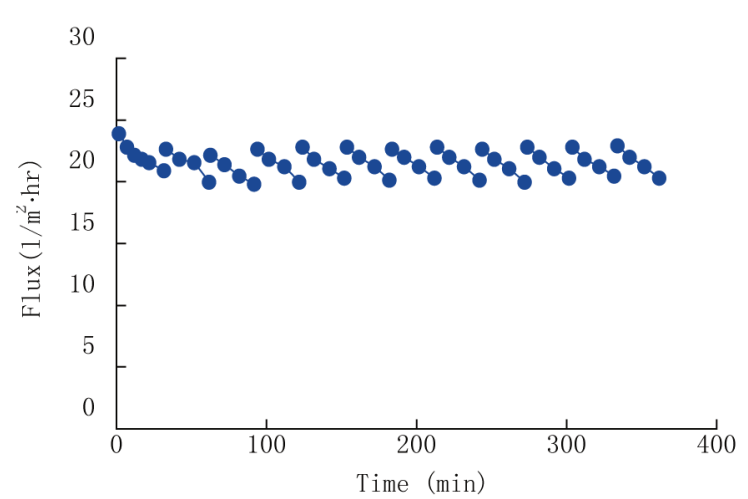

Figure 4. Flux variation with respect to time / 26kPa suction pressure; non-continuous suction operating mode with the device was not eliminated.

value of MBR. (10-15 1/ $\left.\mathrm{m}^{2} \mathrm{hr}\right)$

The permeate flux of intermittent operating mode is more than that of continuous operation and the value of the permeate flux is between $15 \mathrm{l} / \mathrm{m}^{2} \mathrm{hr}$ and $20 \mathrm{l} / \mathrm{m}^{2} \mathrm{hr}$.

The MBR equipped novel device which adopting intermittent operating mode is most effective in this study and the value of permeate flux is between $20 \mathrm{l} / \mathrm{m}^{2} \mathrm{hr}$ and $25 \mathrm{l} / \mathrm{m}^{2} \mathrm{hr}$.

\section{Acknowledgements}

The authors acknowledge the financial support of National 863 Project (2007AA06Z374).

\section{REFERENCES}

[1] A. S. Malik, O. Boyko, N. Atkar and W. F. Young, "A Comparative Study of MR Imaging Profile of Titanium Pedicle Screws," Acta Radiologica, Vol. 42, No. 3, 2001, pp. 291-293. doi:10.1080/028418501127346846

[2] D. W. He, Y. T. Xiao and X. Li, "Treatment of Oil/Water Emulsion by Polyethylene Glycol Ultrafiltration Membrane," Journal of Central south University, Vol. 12, No. 5, 2005, pp. 542-545.

[3] N. Cicek, H. Winna, M.T. Suidan, B. E. Wrenn, V. Urbain and J. Manem, "Effectiveness of the Membrane Bioreactor in the Biodegradation of High Molecular Weight Compounds," Water Research, Vol. 32, No. 5, 1998, pp. 1553-1563. doi:10.1016/S0043-1354(97)00350-3

[4] T. Mukai, K. Takimoto, T. Kohno and M. Okada, "Ultrafiltration Behaviour of Extracellular and Metabolic Products in Activated Sludge System with UF Separation Process," Water Research, Vol. 34, No. 3, 2000, pp. 902-908. doi:10.1016/S0043-1354(99)00208-0
[5] X. C. Wang and J. Wang, "Kinetic Study of Membrane Fouling under Cross-Flow Ultrafiltration Opteration," Environmental Chemistry, Vol. 21, No. 6, 2002, pp. 552-558.

[6] G. E. Wetterau, M. M. Clark and C. Anselme, "A dynamic model for predicting fouling effects during the ultrafiltration of a groundwater," Journal of Membrane Science, Vol. 109, No. 2, 1996, pp. 185-204. doi:10.1016/0376-7388(95)00200-6

[7] M. Cheryan, "Ultrafiltration Handbook," Technomic, Lancaster, 1986.

[8] S. Kunikane, Y. Magara, M. Itoh and O. Tanaka, "A Comparative Study on the Application of Membrane Technology to the Public Water Supply," Journal of membrane science, Vol. 102, 1995, pp. 149-154. doi:10.1016/0376-7388(94)00292-7

[9] T. Jiang, M. D. Kennedy, G. J. Walter, van der Meer, P. A. Vanrolleghem and J. C. Schippers, "The Role of Blocking and Cake Filtration in MBR Fouling," Desalination, Vol. 157, 2003, pp. 335-343. doi:10.1016/S0011-9164(03)00414-4

[10] E. H. Bouhabila, R. B. Aïm and B. Hervé, "Fouling Characterization in Membrane Bioreactors," Separation and Purification Technology, Vol. 22-23, 2001, pp. 123-132. doi:10.1016/S1383-5866(00)00156-8

[11] C. Albasi, Y. Bessiere, S. Desclaux and J. C. Remigy, "Filtration of Biological Sludge by Immersed Hollow-Fiber Membranes: Influence of Initial Permeability Choice of Operating Conditions," Desalination, Vol. 146, 2002, pp. 427-431. doi:10.1016/S0011-9164(02)00527-1

[12] C. Albasi, Y. Bessiere, S. Desclaux and J. C. Remigy, "Filtration of Biological Sludge by Immersed Hollow-Fiber Membranes: Influence of Initial Permeability Choice of Operating Conditions," Desalination, Vol. 146, 2002, pp. 427-431. doi:10.1016/S0011-9164(02)00527-1

[13] C. Albasi, Y. Bessiere, S. Desclaux and J. C. Remigy, "Filtration of biological sludge by immersed hollow-fiber membranes: influence of initial permeability choice of operating conditions," Desalination, Vol. 146, 2002, pp. 427-431. doi:10.1016/S0011-9164(02)00527-1

[14] K. J. Kim, A. G. Fane, C. J. D. Fell and D.C. Joy, "Fouling Mechanisms of Membranes during Protein Ultrafiltration," Journal of membrane science, Vol. 68, No. 1, 1992, pp. 79-91. doi:10.1016/0376-7388(92)80151-9

[15] M. R. Wiesner and S. Chelam, "The promise of the membrane technology," Environment Science and Technology, Vol. 33, No. 17, 1999, pp. 360-366. doi:10.1021/es9930081 